\title{
Organising Ethics: The Case of the Norwegian Army
}

\author{
Ellen-Marie Forsberg ${ }^{1}$, Are Eidhamar ${ }^{2} \&$ Svein-Tore Kristiansen ${ }^{3}$ \\ ${ }^{1}$ Work Research Institute, ellen-marie.forsberg@afi-wri.no; ${ }^{2}$ Norwegian Military Academy, aeidhamar@mil.no; \\ ${ }^{3}$ Norwegian Military Academy, svein-tore@msn.com
}

This article shows how institutionalism, a theory in organisational social science, provides a model for diagnosing organisational challenges that influence the ethical practices and integration in the Norwegian Army. Institutionalism provides tools for analysing the differences between expressed values and actual practices and for understanding the organisational dynamics that unfold at the crossroads of the organisation's formal structure, informal culture and stakeholder relations. In this article we present and discuss such differences and dynamics in the Norwegian Army based on findings from a survey and a number of workshops. We also provide some suggestions for effective implementation of strategies for strengthening ethics in such an organisation. We argue that the perspective taken in this project is also relevant for other highly professionalised complex organisations and that such interdisciplinary research will strengthen practical ethics' potential for real impact.

Keywords: Professional ethics; organisational ethics; the Norwegian Army; institutional theory; interdisciplinarity

\section{Introduction}

During recent years Norway has seen an increase in attention to ethical issues, in society in general, in the defence sector and in the Army Military Academy. The focus on ethics in the defence sector can be explained by several factors. First, the media has drawn attention to several instances of suspected economic criminality and signs of an undesirable culture with regard to camaraderie, favours, etc. in the defence sector bureaucracy ${ }^{1}$. Second, the mandate and tasks of the Armed Forces have changed; most notably, they have become more professional and are more involved in foreign military operations (such as the current engagement in Counter Insurgency Operations (COIN) in Afghanis$\tan )$. This changes the relationship between society and the Armed Forces and creates new issues with regard to professional identity, culture and ethics. In response to such developments, the Minister of Defence launched an offensive action plan with regard to supporting good attitudes, ethics and leadership (the so-called HEL plan) (Ministry of Defence 2006). One of the goals of this plan was that consciousness about attitudes and ethical reflection was to be a part of every individual's behaviour in his or her day-to-day work (p. 4, our translation). As part of the follow-up to this plan, the Military Academy initiated in 2008 a research and development project called Practical Professional Ethics 
in the army. The project was to assist all units in the army in their implementation of the HEL plan as well as generate knowledge about the implementation of ethics programs in the army. This research and development project is the background for this article.

In this article, we specifically address only some aspects of the project, namely those that concern identification and discussion of ethical issues in the organisation and organisational conditions for designing an effective ethics program. As such the article is on organisational ethics. By organisational ethics we understand a branch of applied (or practical) ethics closely related to business ethics, but without the latter's bias towards commercial companies. In this respect organisational ethics includes business ethics, but it is a field with a somewhat larger scope. The discussions on organisational ethics and business ethics are similar as they concern ethical issues within and between organisations or between organisations and society. This article explicitly discusses only the case of the Norwegian Army, but the approach is general and several of the lessons should be applicable to military organisations in other countries as well as other highly professional complex organisations.

The article will have the following structure: we first start by briefly outlining the method of the project. We then present the discourse on which we build our analysis, which is an interdisciplinary discourse of organisation theory and applied ethics. We use an institutionalist approach, stressing three perspectives of the organisation: understanding the organisation as a rational system, a natural system and an open system (Scott 1987). After this we present our results within this theoretical framework. We discuss how ethics programs in the Norwegian Army should take these organisational dimensions into account and how, in general, ethics should be combined with the social sciences when designing effective ethics programs.

\section{Methods}

The research and development project consisted of a literature and document review, a survey and participatory ethics planning workshops in all operative units in the army (except one). ${ }^{2}$ The document review focused on ethically relevant guidance documents, such as the Officer's Code, the value foundation, etc. The literature review focused on professional ethics in general with a special focus on military professional ethics as well as organisational ethics literature. The survey was Internet based and sent to all officers in the operative units in the army in the period between December 2008 and January 2009. The intention was to map the officers' perceptions of the formal and informal ethical discourse as well as their knowledge of the current ethics program. We asked about discourse on different categories of work environment-related issues affecting organisational culture and individual professional integrity. These categories are related to the general ethical principles of welfare, autonomy and justice ${ }^{3}$ but were operationalised to be more adapted to the respondents' context. Five hundred officers responded, amounting to a response rate of $40 \%$. Of those who responded, 236 were commissioned officers, ${ }^{4} 154$ were non-commissioned officers (NCOs), 65 were drafted officers and 33 
were fulfilling their compulsory service. 431 were men, 61 were women, and 8 did not indicate gender. The results were processed in SPSS statistical analysis software, and univariate and bivariate analyses were conducted. All associations reported here are statistically significant (having a $p$ value at 0.05 or less). The questionnaire mostly used multiplechoice response alternatives, including an open response option. The questionnaire also included questions in which the respondents were asked to indicate to what extent different issues were discussed, to what extent they were familiar with core values, etc. In these types of questions the respondents could usually choose between five categories (and 'don't know'). Here we report in three categories, combining 'very high extent' and 'high extent' into 'high extent'. We do so similarly for 'low extent'. As some respondents did not answer all the questions, we report valid percent and note the actual number of respondents for each question.

The workshops were organised as one- or two-day workshops where a cross section of the unit attended, from 10 to 20 participants, including staff and line officers from different levels and sections, as well as union representatives, the chaplain and at least one female officer. Through the workshops we wished to create new organisational spaces where ethically relevant issues could be brought up and discussed based on the professionals' experiences. Before the workshops we had pre-meetings with the units' leaders during which we presented the respective unit's survey results in order to validate our findings and provide input for organisational learning in the unit.

\section{Theoretical perspectives}

The focus in this project originated in part from an earlier project at the Military Academy that reported on a perceived gap between expressed values and actual practice with regard to the treatment of female professionals and showed that female professionals were less integrated in the organisation than men (Kristiansen et al. 2010: 48-50). A project on army professionals on contracts showed that NCOs also suffered from a lack of integration in the organisation (Kristiansen 2009). Our working hypothesis was that a similar gap between the formally expressed values and the informal organisation culture could be found in other ethically relevant areas of the army organisation. Moreover, we wanted to investigate whether the apparent difference in the integration of certain groups in the army implied that there were also gaps in the ethical integration in the organisation. We understood ethical integration as common ethically related discourses cutting across rank and function. Both phenomena would be important to address in the context of an organisational ethics program such as HEL.

In order to address such gaps in the context of organisational ethics, we needed tools for analysing the organisation. In the study of organisations, institutional theory has perhaps been the approach that has best captured the relations between the formal, official organisation and the informal organisational culture and often implicit organisational world views. A further assumption in the project was therefore that institutional theory would help clarify the organisational dynamics that should be taken into account when 
addressing ethical issues in the organisation. Institutional theory is widely used to analyse public administration, and it has, for example, been used in studies of formal and informal structures in the police force ${ }^{5}$. Studying health care sector organisations, Boyle et al. (2001) build on the work of Scott (1987) and claim that many of the ethical challenges of organisations can be understood only by taking these different dimensions into account. Scott's distinction between the institutions as a rational, natural and open system is further interpreted into an ethical context by Boyle et al.

According to Boyle et al., the rational systems approach understands the organisation as having '(1) a visible set of hierarchical authority relations in which (2) work activities are governed by formal rules and clearly defined criteria for evaluation, relations that (3) are designed to pursue some set of goals.' (2001: 31). From an ethical perspective, the rational system includes ethical guidelines and codes of conduct, monitoring and assessment systems, formal ethical responsibility, etc. Moreover, thinking in terms of rational systems allows scrutiny of organisational issues such as workload, the availability of resources, etc. When the organisation is analysed as a natural system, the focus is on the informal sides of the organisation, acknowledging that individuals may have a significant influence on attitudes and conduct in an organisation and that cultures and sub-cultures may flourish more or less decoupled from formal structures, often undermining, replacing or transforming them (p. 33). Taking this informal dimension into account means - in an ethical context - to 'identify the degree to which actual norms, rules, and practices differ from official or formal ones, and then to enquire into how the informal counterparts influence production outcomes, interpersonal relations, and goal attainment' (p. 33). Although there is a need for both formal and informal systems in an organisation, a gap between them that is too wide might give room for hypocrisy, cynicism and disillusionment. In addition to these rational and natural systems approaches to the organisation itself, the open systems approach deals with the relation between the organisation and its environment, on which it is 'dependent for resources, personnel, and legitimacy' (p. 35).

Many mechanisms are at work in the intersection of these three systems, and institutional theory describes the dynamics between the rational, natural and open systems in a way that sheds light on some of the problems with designing effective ethics programs. In this article we use this analytic framework in a crude way compared with the level of sophistication achieved in institutional theory over the last 40 years. Our main point has not been to advance institutional theory but to use the dimensions of this theory that seem to clarify some ethical challenges and conditions for successful ethics work in the army. One important adaptation we are making of Scott's approach is to regard the rational, natural and open system as aspects of an organisation not simply as approaches to the study of organisations. We find this fruitful in our discussions, but this must be understood as an abstraction of a number of complex dynamics.

This project and article can be characterised by a pervasive focus on discourse and could be placed in the category of 'discursive institutionalism' (Schmidt 2008), a variant of institutionalism focusing on change through ideatic development and discourse. An underlying assumption is that ethical issues must be discussable in the organisational public spheres ${ }^{6}$ in order for the organisation to tackle them effectively, an assumption in 
clear coherence with different forms of pragmatist ethics. Framing the issue in terms of spheres or forums for reflection points to some strategies for effectively working with ethics in the organisation, and such an approach justified how we carried out the development aspect of the project. We return to this after presenting some results from the survey, supported by experiences from the project workshops.

\section{Results and analysis}

Here we use the analytic framework briefly outlined previously to present and analyse the most interesting findings from the project. We show differences in how topics are discussed formally and informally and differences in how different groups perceive these discussions. We also identify issues pertaining to the relationship between the organisation and its environment. These results shed light on the project's initial working hypotheses.

\section{Ethics in formal and informal discussions}

We designed the questionnaire to uncover how work life-related ethical issues are discussed in the organisation. The replies show that some issues are discussed more often informally, while others more often formally:

Table 1

\begin{tabular}{|l|l|l|l|}
\hline Ethical issues & $\begin{array}{l}\text { Is discussed } \\
\text { to a large extent }\end{array}$ & $\begin{array}{l}\text { Informal } \\
\text { discussions }\end{array}$ & $\begin{array}{l}\text { In unit } \\
\text { meetings }\end{array}$ \\
\hline $\begin{array}{l}\text { Health, safety and environ- } \\
\text { ment (HSE) issues }\end{array}$ & $29 \%(147)$ & $53 \%(267)$ & $68 \%(340)$ \\
\hline Harassment & $9 \%(43)$ & $56 \%(282)$ & $52 \%(258)$ \\
\hline Freedom of expression & $26 \%(128)$ & $72 \%(360)$ & $41 \%(203)$ \\
\hline Use of drugs and alcohol & $10 \%(50)$ & $67 \%(337)$ & $50 \%(248)$ \\
\hline Justice/equal treatment & $20 \%(100)$ & $69 \%(344)$ & $51 \%(257)$ \\
\hline Relation to civil society & $31 \%(154)$ & $58 \%(289)$ & $73 \%(367)$ \\
\hline
\end{tabular}

The column on the left shows the percentage indicating that this issue was discussed to a large extent altogether. The next two columns show the percentage of respondents indicating that the issues were discussed mostly in informal discussions or in unit meetings (respectively). Other response categories were also given (and the respondents could check several), but these were the ones most frequently used. The total number of respondents varies between 494 and 500 for the different percentages, which are actual percents. Raw numbers are noted in brackets.

We also asked the respondents where they would bring up such issues; for instance with their closest leader, their union representative, the chaplain, fellow officers, family and friends, etc. It is outside the scope of this article to discuss the numbers in Table 1 and the general answers to where the respondents would address issues. Rather, we focus here on the differences in the respondents' replies about to what extent and where the different 
issues are discussed. This reflects their own perceptions, and there are interesting associations between the respondents' replies and their status.

For instance, to the question about where the respondents would discuss issues related to harassment we find interesting gender differences. Whereas $38 \%$ (164) of the men would as a rule discuss harassment with their local union representative, only $23 \%$ (14) of the women would do so. Moreover, $69 \%$ (42) of the women, versus $84 \%$ (360) of the men, would as a rule bring up such issues with their closest leader. With regard to this issue, women turn to family and friends to a larger extent than men. While $25 \%$ (15) of the women would discuss harassment issues with their friends and family, only $5 \%$ (22) of the men would do the same. Although this trend is most prominent with regard to harassment, we see similar numbers with regard to bringing up issues related to freedom of expression to one's closest leader, where $69 \%$ (42) of the women would as a rule do this, versus $82 \%$ (355) of the men. Also in the case of freedom of expression we see that $25 \%$ of the women (15) would discuss this with family and friends, versus $7 \%$ (29) of the men. This suggests that men find somewhat more support in both the formal and informal system and seems to confirm that women are slightly less integrated in the organisation (although the differences are not great). More studies should be conducted on this issue, because if such differences are shown to be more pervasive, this would in itself be an issue of equity and fairness. However, it may also be a matter of excluding voices from formal and informal discussions. Women do not necessarily represent unique moral perspectives, but there is a risk that morally relevant experiences and views are ignored when women are more reserved towards their organisation.

With regard to position, the survey data show that the rational system is more important to the commissioned officers than to the NCOs. The distinction between commissioned officers and NCOs clearly appears with regard to how well integrated they are in the unit's infrastructure, where the officers with higher formal rank have a larger formal and informal network to mobilise in the organisation. For instance, while $26 \%$ (62) of the commissioned officers would discuss issues related to freedom of expression with other leaders within or outside the unit, only $12 \%$ (4) of the NCOs would do this. This was also confirmed when we asked in what forums they would discuss ethically related issues, the distance between them and the unit management, etc. We see for specific issues that commissioned officers, more than other groups, seek support among other officers and in the formal established structures, including the 'ombudsman', the work environment committee and the chaplain. The survey results also suggest that the commissioned officers dominate the formal meetings and forums where ethically relevant issues are formally brought up. For instance, $59 \%$ (139) of the commissioned officers report that unit meetings are one of the places where issues related to justice and equity are discussed most often. Only $43 \%$ (14) of the drafted personnel report the same. Moreover, when asked where discussions of freedom of expression most often take place $6 \%$ (2) of the officers in compulsory service say that they are discussed in management meetings, while $36 \%$ (86) of the commissioned officers say the same. There is also a similar pattern for other issues. This can be explained by the fact that the engaged personnel do not take part in all unit meetings. Moreover, the meetings they do take part in discuss such issues to a 
lesser extent. Commissioned officers, because of their function and rank, attend other formal arenas in the organisation compared with the NCOs, who on a regular basis mainly attend team and platoon meetings.

The workshops confirmed that the perceptions of the organisation and its context can vary substantially between levels and functions in the units. The workshops also showed that the units have few forums where officers can discuss ethical issues across rank, function and section: the formal organisational structure and the command and control system are not designed for collaboration across rank and function. In this regard, our project resonates with the study on army professionals on contracts referred to previously.

Although these findings are not surprising, they are not trivial from an ethical point of view. Except for the vast practical consequences this information chain break might have, it may also have important ethical consequences. If lower level meetings to a lesser extent address ethical issues, and there are few crosscutting forums, large groups in the army may well end up with a different understanding of the organisational values and norms than those in higher positions. The NCOs may easily be distanced from many of the ethically relevant discussions and the ethical infrastructure resources (like the HEL plan and the value foundation) of the rational system. Moreover, valuable field experience might never get communicated to the top. When, for instance, battalion commanders are not in touch with the discussions in the platoons they will have access to less information about the culture among the soldiers and their behaviour. This again makes it harder to shape a desired culture.

The risk of not including drafted soldiers and NCOs in broader organisational forums is that questions of values and ethics become a private issue or left to sub-cultures that flourish in a natural system out of touch with the formal and explicit values and codes of conduct. An example of this phenomenon is perhaps the sub-culture that evolved in a Norwegian mechanised infantry company (Mek 4) in Afghanistan, consisting to a large extent of drafted soldiers and NCOs. Professionals from this company attached the 'Punisher' scull emblem on their uniforms ${ }^{7}$ and used Norse war symbols and Viking helmets as a means to create group cohesion before departing into hostile territories. Moreover, some company members stated in interviews that 'warring is better than sex' and that they killed without reflecting much about it ${ }^{8}$. Drafted soldiers and officers in the field are precisely those professionals that most frequently meet important stakeholders and affected parties such as civil populations, aid workers, the Afghan Army and police, and not least the enemy. It is in the meeting with these parties that military ethics is applied (or not applied) to its fullest. The significance of this becomes even more acute when we take into account the army's operational pattern in which a decentralised command and control system relies to a great extent on the ethical reflection of ordinary soldiers and NCOs. Ultimately, undesirable sub-cultures may in an army setting have consequences for human lives, and this is an argument for the need for better aligning and integrating of the rational and natural systems. 


\section{Ethics and the organisation as an open system}

The previous example illustrates how sub-cultures may evolve and how their rituals, symbols and language from an outsider perspective are quite far from the public, civil or common morality (cf. Gert 2004 and Tranøy 1998). Even if one might understand the need for building group spirit and a sense of collective motivation in an extreme situation, using Norse war symbols is not acceptable from the point of view that Norway's role in Afghanistan is presented as Afghan competence building and ensuring safety and stability for Afghan civilians. ${ }^{9}$ There is a balance with regard to how far it is possible to go in positioning such tasks into a warrior mythology without putting the perceived legitimacy of the Norwegian forces at risk, both at home and abroad. In our view, this situation warrants addressing the organisation as an open system, which brings with it questions of legitimacy.

Regarding the organisation as an open system involves seeing how it interacts with its environment. Institutional theory describes how an organisation must operate in a balance between creating external legitimacy and operating in a stable and efficient way in its core activities (cf. e.g. Meyer \& Rowan, 1977). Suchman (1995) describes in his seminal article organisational legitimacy as an anchor point for understanding organisation-environment conditions (p. 571) and claims that ' $[1]$ egitimacy is a generalized perception or assumption that the actions of an entity are desirable, proper, or appropriate within some socially constructed system of norms, values, beliefs, and definitions.' (p. 574). Legitimacy can be created by conforming to political and other societal expectations (for instance, conveyed through the media). These expectations concern efficiency in the use of public resources and goal achievement, but expectations also show coherence with a presumed common morality in society. In some cases these two expectations may create tensions. ${ }^{10}$ If there is a perceived inconsistency between an organisation's values and the public common morality, rational systems programs such as ethics programs might be seen as required by the organisation's owners (politicians, board of directors, etc.). This might be regarded as cumbersome by the operative organisation seeking to optimise efficiency by drawing on the natural systems resources such as informal routines and commonly acknowledged standard operation procedures - in order to minimise transaction costs and to allow pragmatic and efficient problem solving. In our project we realised that some operative leaders were reluctant to devote time to ethics projects because they prioritised the duties they needed to report on in the chain of command.

Additional tensions may arise when the organisation is exposed to different sets of expectations. As an open system, the army not only seeks conformity with the Norwegian society's values but army professionals also interact with other significant stakeholders and adjust to their value systems. The troops in Afghanistan are exposed to other nations' warrior cultures (such as American and Afghan), and these cultures (and their professional standards) are closer - at least geographically - than legitimising programs at home in Norway. For army professionals, legitimacy in the eyes of closer stakeholders like the American troops may have a stronger emotional force than domestic concerns. If these forces pull in different directions, the result can be tensions and ambivalence. 
An important stakeholder of the Norwegian Army in Afghanistan is the local population, and in the survey we asked some questions about the army's relationship with civil society. One would perhaps expect that those who were mostly involved in foreign operations would be those who discussed this relationship the most. This was, however, not the case. In fact, some of the most professional battalions in the army (with most personnel in Afghanistan) were actually among those that most reported that they discussed this relation to a low extent (38\%, 14 respondents). In the population as a whole, $25 \%$ (123) reported that they discussed this to a low extent. ${ }^{11}$ When confronted with these results, one of the battalions that scored low on discussion of topics related to civil society explained this number with the fact that the battalion consisted of professional soldiers who were properly educated, and that they therefore did not need to discuss such obvious issues. However, when regarded in light of the Punisher episode they might have dismissed the issue too easily. One should question whether there is an inherent tension between the rational system and the open system at play here. The open system is perhaps most prominent at the boundaries of the organisation - and perhaps necessarily so, as the organisation here requires flexibility and adaptability. At the periphery of the rational system, the natural system with its culture flourishes in its open environment. However, at the same time it is here, in the most extreme unfolding of the profession, that the legitimacy of the organisation is most vulnerable. It is therefore crucial for the rational system to be prominent here. Yet, in one of the most operative battalions $70 \%(26)$ answered that they were not familiar with the HEL plan at all (in the army as a whole $52 \%, 260$ respondents, answered this). ${ }^{12}$ This does not indicate that the officers are insensitive to ethical dilemmas in the field. However, it does suggest that there is a need to strengthen the rational system ethical infrastructure in the organisational periphery and to install mechanisms that cater for wider ethical reflection across platoons and companies. This might not entirely eliminate extreme expressions in situations of great moral and existential pressure, but it is a way for the organisation to address such issues upfront and in a systematic way.

\section{Integrating ethics in the organisation}

In the previous section we have identified important ethical challenges that can be conceptualised in terms of the dynamics between the army as a rational, natural and open system. In this section, we address what we perceive as important approaches when working with ethics in such a context. The findings presented earlier indicate that the main challenge is to integrate the organisation in such a way that the rational, natural and open systems reinforce a common ethical 'core'. This core must be further developed and operationalised in the dynamics between these systems so that it does not become a straightjacket pre-defined from the top. In the following paragraphs, we discuss what we perceive as important elements for bridging the gaps between the systems. 


\section{Bridging the gap between the formal and informal: the role of leaders}

When the Minister of Defence initiates an ethics program to respond to bad media attention and political pressure, it is an action to uphold the necessary societal legitimacy of the Norwegian defence. The leader of a highly operational unit, however, is in a position much closer to the actual task solution and thus is likely to experience pressure between top-level legitimacy measures and bottom-level task solution. These leaders are crucial for bridging the formal directives and the informal culture - the rational and the natural systems - because they are often an influential part of both. Leaders with a strong position can draw on both systems and can bring the systems together. This can be an important resource for achieving ethical change, in the sense that the leader can change undesired culture by 'articulating a vision, by paying attention to, measuring, and controlling certain things, by making critical policy decisions, and by recruiting and hiring personnel who fit with their vision of the organization' (Trevino \& Nelson 1995: 201). However, a strong leader can also be a problem, if the leader is not committed to the ethical values assumed to maintain the societal legitimacy of the organisation.

The leaders in this survey seem in general to have a strong position, but as we saw earlier, there are differences across the organisation with respect to how the respondents regard their leader: women in the army seem to have a slightly more distanced relation to their nearest leader. In order to enhance organisational learning and development of moral motivation and judgement among the subordinates and the leaders, the leaders need especially to be open to the contributions by women and other groups that may not be fully integrated in the rational and natural system in order to take advantage of the organisational resources of these groups and strengthen their beliefs in themselves as moral actors in the organisation. At the same time, the leaders must signal their commitment to the values in the rational system, both in their communication and action. In the survey, $40 \%$ (199) answered that the higher officers to a great extent are positive role models for the core values, ethics and good attitudes.

\section{Bridging the gap between the formal and informal: opening up the systems}

From an institutional perspective, leaders are not only leaders of a formal and informal system but they are also inherently embedded in it. Although they feel the pressure to comply with and advance the 'official' values, they are also socialised into the values of the natural system. This holds for a profession-based institution like the army in particular, where all leaders through their military education and career have been infused with the norms and values of the profession. If there are ethical reasons to want to change or improve a part of the culture (which is assumed in the HEL program), the natural system must be 'opened up', making it receptive to change. Weick (2001) presents some instruments for creating change in loosely coupled systems: ${ }^{13}$ inducing doubt in formerly selfevident perceptions; resocialisation; equalisation of participation in different forums; distraction of constant variables; and dependability and immediate feedback (p. 381). It is beyond the scope of this article to explain these notions in any detail; it is sufficient to note that cultural changes can be forged. A 'softer' approach would perhaps be to strengt- 
hen the position of civilians employed in the army. This might lead to a more critical discussion of implicit internal cultural practices that appear unacceptable from a societal point of view. ${ }^{14}$ It is also worth noting that when women turn to their families and friends to discuss difficult issues in their professional life they at the same time reinforce the relations with civil society. In seeking support at home (within the scope of civil morality) rather than at work (within the scope of professional morality), they may bring the civil values more strongly back into their work situation. ${ }^{15}$

\section{Bridging the gap between the formal and informal: strengthening the discourse}

One of the main tasks of the leader in bridging the rational and the natural system is to strengthen the discourse in the organisation's public spheres, ensuring that topics for informal discussions also inform the formal discussions in the established forums across the organisation. Dialogue is necessary to make institutional culture, structures and 'myths' (Meyer \& Rowan 1977) explicit, which again is necessary to challenge them and make them subject to critical discussion and moral judgement.

This ethical reflection must be more thoroughly integrated in the organisation, not least (as we have seen) because some ethical issues seem to a lesser extent to be discussed at lower-level forums and lower-level officers are not present at the kind of meetings where many important ethical issues are discussed. Forums must therefore be made where a cross section of the organisation can discuss ethically relevant issues, and where the lowest level officers are also included. However, merely creating such forums is not enough. Foucault (1977) shows how discourse and power are interconnected. Forums can simply be a way of maintaining existing power relations, and creating new forums for ethical discussion may involve creating new forums where existing power structures can unfold.

Gordon et al. (2009) provide an interesting example from the New South Wales police force of how creating forums, whistle blowing systems or other structures is not sufficient for ethical change if basic power structures are not brought into the daylight. In their view, making forums and talking about the implicit (and explicit) myths and values that shape the professionals' choices and actions do not necessarily change the power structures that maintain the culture. ${ }^{16}$ Rather, they report that power relations silenced critical voices and made ethics a matter of compliance' (2009: 85). Such insights lay the ground for new studies of how codes of conducts and other moral instruments 'are used in practice by organisational members in their local, situated, organisational contexts: contexts that are invariably saturated with uncertainty, ethical pluralism and the multiple constituting and conflicting webs of power' (Tadajewski et al. 2011: 35, citing Clegg et al. 2007: 113). Moreover, they remind us that new discursive forums should, as far as possible, be designed to neutralise inhibiting power practices. Among other things, it is important to make sure that a more thorough integration of the organisation's discourse does not mean the transformation of the minority voices into a majority mainstream; integration must involve respecting value differences. 
In some of the project workshops, we attempted to address power relations in the units and make them explicit. However, making power relations explicit is often a sensitive issue, where fear of subsequent sanctions may inhibit the free expression of peoples' minds. It is therefore hard to say what longer-term effect it had to make power relations an explicit focus in the workshops. Most likely, in order to have effect such interventions cannot be on an ad hoc basis, but must be a systematic focus for democratising the organisation.

\section{The effectiveness of ethics programs in the Norwegian Army}

Before concluding, we will briefly discuss the HEL plan on the basis of the project's findings. The initial HEL plan required actions related both to the rational and natural systems aspects of the defence sector. The updated HEL plan for 2009-2012 structured the actions into four groups: a) building knowledge and competencies, b) building culture, c) systems and structural aids, and d) social responsibility (Ministry of Defence 2009). It also required the units in the defence sector to report on the actions they had taken related to these four focus areas. Both HEL plans required the units to make local action plans related to attitudes, ethics and leadership.

The ethics programs in the defence sector (both before and after HEL was launched) have established an ethical infrastructure in the rational system. There has been a focus on creating new value documents, codes and programs intending to instil an explicit identity and normative framework upon the army professionals (building on historical references). The Norwegian Defence has produced or revised several ethical documents, including an officer's code, a value foundation and the army core values (respect, responsibility and courage), and units in the army are in the process of creating their own value foundations. These documents of professional ethics are meant to be used in the education of soldiers and officers; and as a normative basis in the units. Two defence institutions have established an ethical council, and in 2011 an ethical council for the whole defence sector became operative. Many of the Defence institutions have also published ethics leaflets, etc. Two whistle-blowing hotlines have been established. All these activities come in addition to ordinary ethics training in the military education system. The organisation thus uses its rational, formal structures to 'implement' ethics.

We see that some of these means have been more successful than others in the sense of being used. The whistle-blowing hotline does not seem to be used much. Of the 269 people who had experienced objectionable affairs, only 3 had used the hotline. When the respondents were asked where they would normally bring up questions related to HSE, harassment, etc. around 0.8 to $2.4 \%$ (4 to 12 individuals, depending on the issue) would use the hotline. The hotline is an infrastructure intended to be as free from informal power structures as possible. Yet, it is not perceived as an important channel for raising ethical issues. The most successful ethical instrument seems to be the core values (respect, responsibility and courage). About $41 \%$ (203) report that these values have a function in practice. In the project workshops, the core values were frequently mentio- 
ned. However, these values are just as much a reinforcement of the existing culture as an instrument for dealing with ethical challenges, and this can perhaps explain its wide adoption.

Given that the institution's ethical infrastructure is more or less in place, the most important HEL challenge is, in our opinion, building a desired culture, as the ethical issues that have been perceived as a challenge in the defence sector in the last decade are indeed related to organisational culture. Addressing cultural aspects is perhaps among the more challenging aspects of HEL, precisely because they flourish in the interface of the rational, natural and open system. Using an institutional framework, we were able to identify important cultural challenges and also identify some important strategies for bridging organisational gaps that hinder ethical reflection and moral learning. We believe that taking the lessons described in this article seriously will increase the chance of designing a well-targeted and effective ethics program in the army.

The development part of the project reported on here was an attempt to turn the HEL plan into locally anchored bottom-up strategies. By initiating workshops with broad participation, we wanted to mobilise not only the formal dimension of the organisation but also to reach into the informal sphere. We wanted to create new organisational public spheres where issues that were mostly informally discussed could be brought into a formal situation; i.e. we wished to bridge the gap between the organisation as a rational and as a natural system. The reason was to inform the rational system so that it could be better adapted to the needs, concerns and worldviews expressed (or implicit) in the natural system and to integrate the perhaps decoupled elements more tightly into an organisational public sphere where issues could be subject to critical discussion. We also encouraged the units to establish such cross-unit discussion forums that would meet regularly to continue this integration. These workshops were simply a beginning of this kind of ethics work in the army and were primarily an attempt to start a process. Moreover, it was outside the scope of the project to challenge the units in the way we here recommend. There is therefore a risk that if the units are not further challenged the workshops will remain a surface activity carried out in order to satisfy directives coming from above and not in commitment to real change. Even if it is important to continue with action research projects in this field, it is clear that ethics cannot be the responsibility of researchers; it must be the responsibility of the leaders. This involves a challenge to individual army leaders in creating and maintaining space for ethical reflection. It also involves a challenge to the Military Academy in educating reflexive officers who are able to instil critical, ethical reflection in their organisations.

\section{A final reflection on ethics and organisation}

Practical ethics is often focused on conceptually analysing practical ethical issues, developing normative frameworks (such as codes of conducts), etc. Although this is important, there is also a need for a focus on the implementation or unfolding of ethics in social systems, like in organisations. Practical organisational ethics requires not only formulation of ethical goals, values and principles for right action but also an understanding of the organisation in which the goals and values are supposed to work. This involves going outside of the traditional moral disciplines of theology and philosophy and looking more to the social sciences such as sociology and ethnology. If real change is among the goals of practical ethics, more research is needed on how to 
make ethics work in practice. For instance, in some cases, organisational measures, like establishing forums for reflection across rank and function, might have to be implemented in order to make an organisation receptive to difficult ethical discussions. Of course, it is still important to note that having the organisational infrastructure for deliberation is a necessary, but not sufficient, condition for ethical reflection. In order to use this infrastructure to its purpose, normative frameworks (moral theories, principles or codes) are still necessary to provide moral concepts with which to discuss practice. Without moral concepts there might well be reflection but not ethical reflection. Moreover, including stakeholders or lay people outside the organisation in such ethical discussions may open up for even wider ethical perspectives and critical challenge of internal assumptions, although it may also lead to defensive reactions of the organisation (see for instance Jensen et al. 2010: 42-43).

This article has used an institutionalist framework for analysing challenges related to working effectively with ethics in the Norwegian Army. Our working hypotheses about the ethically relevant gaps in the organisation seemed to be confirmed by the findings in the project. Indeed, we have suggested that the gaps in the ethical integration can be part of the explanation of the gaps between the expressed values and the actual practices. On this basis, we have discussed how such gaps can be bridged. In this article we have seen that an organisational analysis brings out the specific challenges that help or hinder the implementation of ethics program. This seems to support the idea that we need to understand the organisational context in order to work with ethics in an effective way. There is nothing particular about military organisations in this respect. As noted earlier, Boyle et al. have taken a similar perspective on health care organisations. The perspective also seems fruitful for other kinds of organisations of a certain complexity and institutionalised culture (like highly professionalised ones). Each organisation will have its own unique profile of ethical challenges, but all organisations may have in common ethical challenges that can only be effectively tackled by ethics programs informed by an analysis of organisational dynamics (as the analysis in this article has sought to demonstrate). We therefore call for more case studies and comparative studies contributing to further explore how organisational knowledge can inform ethics in practice.

\section{Acknowledgements}

We would like to thank the Norwegian Army for funding this work and the Military Academy for facilitating the project's implementation. We also thank Eirik Nilsen, formerly employed at the Military Academy, for assisting with Questback survey and Migle Gamperiene at the Work Research Institute for assisting with the statistical analysis. We would also like to thank Lene Bomann-Larsen (the Norwegian Military Academy), Frans Brom (the Dutch Rathenau Institute), two anonymous reviewers for Nordic Journal of Applied Ethics, the journal's editors, as well as colleagues from the Work Research Institute, for helpful comments to earlier drafts of the article. Since the work was carried out two of the authors have changed jobs. Our acknowledgements go to Oslo and Akershus 
University College (where Forsberg is currently employed) and Steria (where Kristiansen is employed) for the time spent on the final revisions of the manuscript.

\section{Notes}

1 See for instance VG, 12.12.07. Mener korrupsjonen i Forsvaret har større omfang. Retrieved 13 March 2011 from http://www.vg.no/nyheter/innenriks/artikkel.php?artid=189908. See also Dagens Næringsliv, Magasinet. Subsidiepilotene. 21/22 November 2009.

2 By 'operative unit', we mean battalions and equivalents.

3 For the centrality of this set of principles, see e.g. Forsberg 2007: 151-157.

4 Professional commissioned officers are officers who have three years' education at the Military Academy and have a career in the Army.

5 See for instance Crank \& Langworthy 1992.

6 See for instance Sproule 1989 \& Pålshaugen 2002.

7 The Punisher is an extremely violent comic book figure that is supposed to punish evil. Two movies have also been made based on the comic.

8 VG, 27.09.10. Dødninghoder sprayet på afghanske hus. Retrieved 13 March 2011 from http://www.vg.no/nyheter/utenriks/artikkel.php?artid=10036791; VG, 27.09.10. - Å krige er bedre enn sex. Retrieved 13 March 2011 from http://www.vg.no/nyheter/innenriks/artikkel.php?artid=10036779

9 Retrieved 20 April 2011 from http://www.regjeringen.no/nb/dep/fd/aktuelt/taler_artikler/ ministeren/taler-og-artikler-av-forsvarsminister-gr/2010/derfor-er-vi-i-afghanistan.html?id=610862

10 See for instance Lunde 2009 for a discussion of the Norwegian Defence's relation to societal values.

11 One should note here that some respondents later told us that they had been unsure whether we here meant civil society in Norway or abroad. Our intention had been to include both, but some may have interpreted this in a way that led to an underreporting of this discussion. However, if so, this should be a systematic error not affecting the difference reported here.

12 Of course, this does not mean that the rational system is absent, but it demonstrates that an important ethical instrument of the formal system is not thoroughly integrated.

13 We do not want to engage in the discussion about the Army as a loosely or strictly coupled system but simply want to point to some instruments for changing the system from within.

14 Kanter (1977: 209) shows that minority groups need to have about $20 \%$ participation in an organisation in order to start affecting the majority culture.

15 This might reinforce the perception of their being carriers of other value sets than their male colleagues.

16 There are many perspectives on power (for an overview see, for instance, Haugaard 2002 or Clegg 1989). Here we simply want to illustrate the point and use Gordon et al.'s (2009) article as a way to do it.

\section{Literature}

Boyle, J.P., DuBose, E.R., Ellingson, S.J., Guinn, D.E. \& McCurdy, D.B. (2001) Organizational Ethics in Health Care: Principles, Cases, and Practical Solutions. San Francisco: Jossey-Bass. Clegg, S.R. (1989) Frameworks of Power. London and Newbury Park: Sage Publications. 
Clegg, S., Kornberger, M. \& Rhodes, C. (2007) Business Ethics as Practice. British Journal of Management, 18, pp. 107-122.

Crank, J.P. \& Langworthy, R. (1992) An Institutional Perspective on Policing. The Journal of Criminal Law and Criminology, 83, pp. 338-363.

Forsberg, E-M. (2007) A Deliberative Ethical Matrix Method - Justification of Moral Advice on Genetic Engineering in Food Production. Dr. Art. Dissertation. Oslo: Unipub.

Foucault, M. (1977) Discipline and Punish. London: Allen Lane.

Gert, B. (2004) Common Morality: Deciding What to Do. New York: Oxford University Press.

Gordon, R., Clegg, S. \& Kornberger, M. (2009) Embedded Ethics: Discourse and Power in the New South Wales Police Service. Organization Studies, 30, pp. 73-99.

Haugaard, M. (ed.) (2002) Power. A Reader. Manchester: Manchester University Press.

Jensen, K.K., Forsberg, E-M., Gamborg, C., Millar, K. \& Sandøe, P. (2010) Facilitating Ethical Reflection among Scientists Using the Ethical Matrix as a Tool. Science and Engineering Ethics, 17 (3), pp. 425-445.

Kanter, R.M. (1977) Men and Women of the Corporation. New York: Basic Books

Kristiansen, S-T. (2009) Militore erfaringer i bruk: metodikk for erfaringsbaserte loringsprosesser: evaluering av avdelingsbefalsordningen i Horen. Fagrapport 2009:1. Oslo, Krigsskolen.

Kristiansen, S-T., Boe, O.C. \& Skjæret, S.W. (2010). Ikke en av gutta! - et mangfoldsperspektiv på inkludering av kvinner i Forsvaret. KS Fagrapport 2010: 1. Oslo: Krigsskolen. Retrieved 24 February 2011 from http://www.krigsskolen.no/downloads/Ikke\%20en\%20av\%20gutta!.pdf

Lunde, N.T. (2009) Profesjonsetiske strategier: Nasjonal konsensus, liberal tilpasning og konservativ avskjerming. In Krigerkultur $i$ en fredsnasjon, eds. H. Edström, N.T. Lunde \& J.H. Matlary, J.H, pp. 156-197. Oslo: Abstrakt forlag.

Meyer, J.W. \& Rowan, B. (1977) Institutionalized Organizations: Formal Structure as Myth and Ceremony. American Journal of Sociology, 83, pp. 340-363..

Ministry of Defence (2006) Handlingsplan for forsvarssektoren. Holdninger, etikk og ledelse. Retrieved 3 March 2011 from http://www.regjeringen.no/upload/FD/Dokumenter/Handlingsplanforholdningeretikkogledelse.pdf

Ministry of Defence (2009) Handlingsplan. Holdninger, etikk og ledelse. Revidert handlingsplan for forsvarssektoren for perioden 2009-2012. Retrieved 3 March 2011 from http://www.regjeringen.no/upload/FD/Temadokumenter/Handlingsplan_2009-2012_nytt-omslag.pdf

Pålshaugen, Ø. (2002) Discourse Democracy at Work. On Public Spheres in Private Enterprises. Concepts and Transformation, 7, pp. 141-192.

Schmidt, V.A. (2008) Discursive Institutionalism: The Explanatory Power of Ideas and Discourse. Annual Review of Political Science, 11, pp. 303-326.

Scott, W.R. (1987) Organizations: Rational, Natural, and Open Systems, 2nd ed. Upper Saddle River, NJ: Prentice Hall.

Sproule, J.M. (1989) Organizational Rhetoric and the Public Sphere. Communication Studies, 40, pp. $258-265$.

Suchman, M.C. (1995) Managing Legitimacy: Strategic and Institutional Approaches. Academy of Management Review, 20, pp. 571-610.

Tadajewski, M., Maclaren, P., Parsons, E. \& Parker, M. (2011) Key Concepts in Critical Management Studies. Los Angeles: Sage.

Tranøy, K.E. (1998) Det åpne sinn. Moral og etikk mot et nytt årtusen. Oslo: Universitetsforlaget.

Trevino, L.K. \& Nelson, K.A. (1995) Managing Business Ethics. Straight Talk About How To Do It Right. New York: John Wiley \& Sons Inc.

Weick, K.E. (2001) Making sense of the organization. Oxford: Blackwell Publishers. 